\title{
The Effect of N-Methyl-Formimino-Methylester on the Neural Olfactory Threshold in Albino Mice*
}

\author{
C. Schmidt ${ }^{1}$, U. Schmidt ${ }^{1}$, W. Breipohl ${ }^{2}$, and F. Effenberger ${ }^{3}$ \\ ${ }^{1}$ Zoological Institute, University of Bonn, FRG \\ ${ }^{2}$ Anatomical Institute, University of Essen, FRG \\ ${ }^{3}$ Institute of Organic Chemistry, University of Stuttgart, FRG
}

\begin{abstract}
Summary. The effects of $\mathrm{N}$-methyl-formimino-methylester were studied in albino mice. Very short exposure ( 0.5 and $1 \mathrm{~s})$ to the concentrated vapour led to an increase of the neural olfactory threshold to geraniol by a factor of $10^{5}-10^{7}$. There was a slow recovery of the olfactory sensitivity and after about 40 days the threshold values returned to normal.
\end{abstract}

Key words: Olfactory threshold - Olfactory blockade - N-methyl-formimino-methylester - Mouse

\section{Introduction}

A common approach to studying the function of the olfactory system has been to destroy some parts of it by surgical or chemical means, and to observe the resulting changes in morphology and behaviour or the regeneration of the affected sensory structures. The time course of regeneration phenomena in the olfactory epithelium depends not only on the species investigated but also on the method applied - for example, the kind of chemical compound used for the blockade [4]. One of the chemicals that can cause a remarkable loss of olfactory sensitivity is N-methyl-formimino-methylester (MFM) [3]. The first sign of an olfaction-blocking action appeared during synthesis of the substance, when accidentally inhaled MFM vapour was found to result in anosmia of immediate onset and several weeks' duration [2]. Such a potent blocking agent would appear to be a useful tool for the study of various problems in olfaction. In the present study, the effect of MFM on the olfactory system of laboratory mice is examined by electrophysiological methods.

\footnotetext{
* Supported by the Deutsche Forschungsgemeinschaft and ABM Ia2-5100

Offprint requests to: Prof. Dr. U. Schmidt, Zoologisches und Vergleichend-Anatomisches Institut der Universität Bonn, Poppelsdorfer Schloß, D-5300 Bonn 1, Federal Republic of Germany
} 


\section{Materials and Methods}

Twenty-seven adult male albino mice (NMRI strain) were exposed to the vapour of N-methyl-formimino-methylester. A $50-\mathrm{ml}$ syringe fitted with an expandable tube that could be placed over the animal's nose was filled with the concentrated gas, which was then released over a period of 0.5 or $1 \mathrm{~s}$ (ca. 20 or $40 \mathrm{ml}$ ).

Permanently implanted tungsten electrodes were used to monitor the neural activity in the olfactory bulbs of waking animals and the evoked response to various concentrations of geraniol as a measure of olfactory threshold [8]. Because the functional life of such electrodes is limited, the electrodes were implanted prior to gas exposure in six of the mice and at various times thereafter in the others. The normal activity of the bulb and the evoked-potential threshold to geraniol were recorded prior to the exposure to MFM, and repeatedly during the 45 days following exposure.

This method enables the neural olfactory threshold of each individual to be determined over a period of several days. During the first 17 days following MFM administration the animals' weights were checked daily.

\section{Results}

The method of exposure to the vapour was tested in pilot experiments, and the amount of $\mathrm{N}$-methyl-formimino-methylester required for olfactory blockade was established. Experiments in which mice were exposed to the concentrated gas $(0.25 \mathrm{ml}$ MFM vaporized in a $10-1$ exsiccator) for 2 min were lethal in all cases. Shortly after MFM inhalation distinct swellings of the conjunctiva and the nasal mucosa appeared, accompanied by an increased production of mucus. The animals breathed entirely through the mouth, with a snapping noise; food was persistently refused. The serous body cavities were conspicously distended and the hair of some animals began to fall out.

In the experiments with which we are concerned here the vapour was applied with a syringe for a much shorter period (group A: $0.5 \mathrm{~s}$ conc. gas, 14 animals; group B: $1 \mathrm{~s}$ conc. gas, 13 animals). Whereas the mice exposed for only $0.5 \mathrm{~s}$ ( $2-3$ breaths) suffered no obvious damage, the 1-s exposure produced marked side effects (e.g., pilo-erection, gasping breath, apathy, oedema in the serous cavities, loss of body weight). The weights of the mice in the two groups during the first 17 days after exposure reflect this difference. All animals in group B suffered severe weight loss, and after 7 days $50 \%$ of them had succumbed to the toxic side effects of the substance (Fig. 1b). The weight curve for those in group A, with few exceptions, exhibited only the natural fluctuations (Fig. 1a).

Though no major effects could be seen in group A, a constant effect of MFM developed in the electrical activity of the olfactory bulb. This is demonstrated in animal A2 whose implanted electrode remained functional for 3 weeks (Fig. 2). The oscillations (induced waves) typical of olfactory-bulb activity were recorded before exposure, but these potentials ceased within $24 \mathrm{~h}$ after inhalation of the gas. The reappearance of the normal pattern of neural activity was extremely slow; after 22 days the waves were still hardly discernible. Olfactory sensitivity was also severely affected. Whereas the initial neural-response threshold to geraniol was $10^{-6}$ vol\% $\left(=5 \times 10^{7}\right.$ molecules $/ \mathrm{cm}^{3}$ air $)$, even after 22 days the sensitivity of A2 remained lowered by a factor of $10^{4}$. 

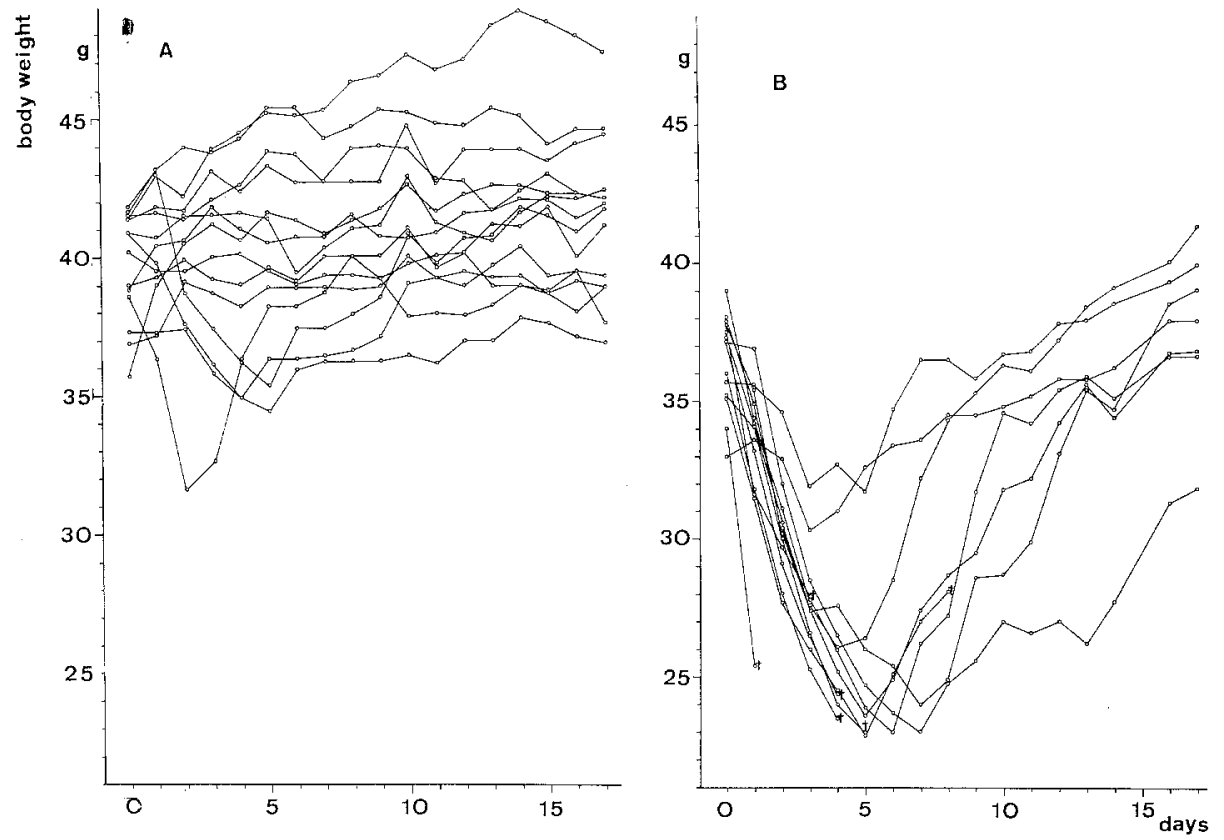

Fig. $1 \mathrm{~A}$ and B. Weight changes in mice following treatment with MFM. A Exposure for $0.5 \mathrm{~s}$ (conc. gas phase), B exposure for $1 \mathrm{~s}$ (conc. gas phase). Ordinate: body weight (g); abscissa: days after exposure $(0=$ weight on the day of exposure)

Fig. 2. Activity of the olfactory bulb of animal A2. b: before administration of MFM; 1,8 , 22 days after administration.

The thresholds to geraniol measured on each of these days are shown on the right (vol. \%)

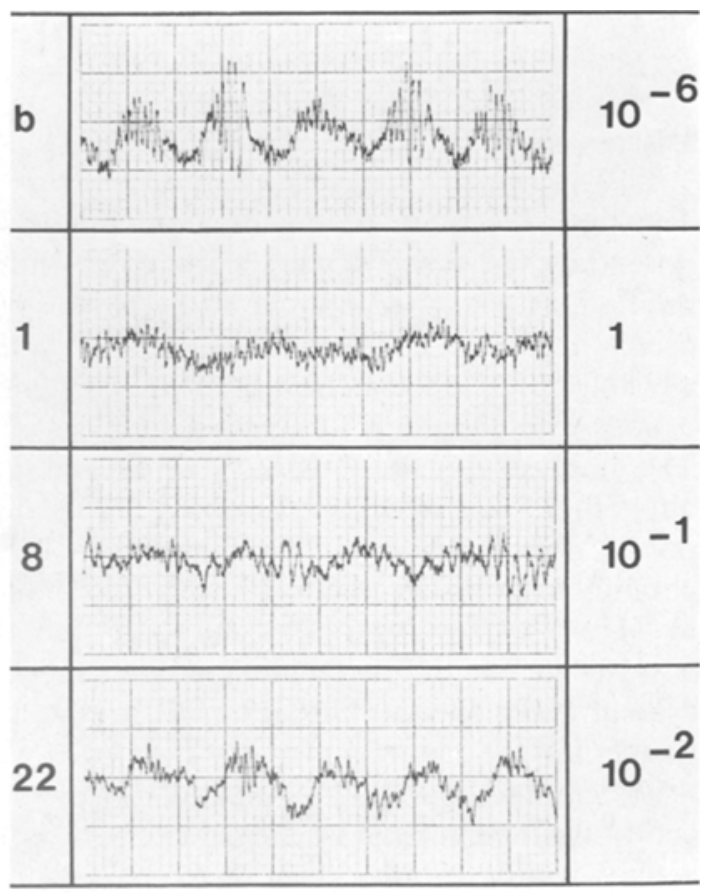




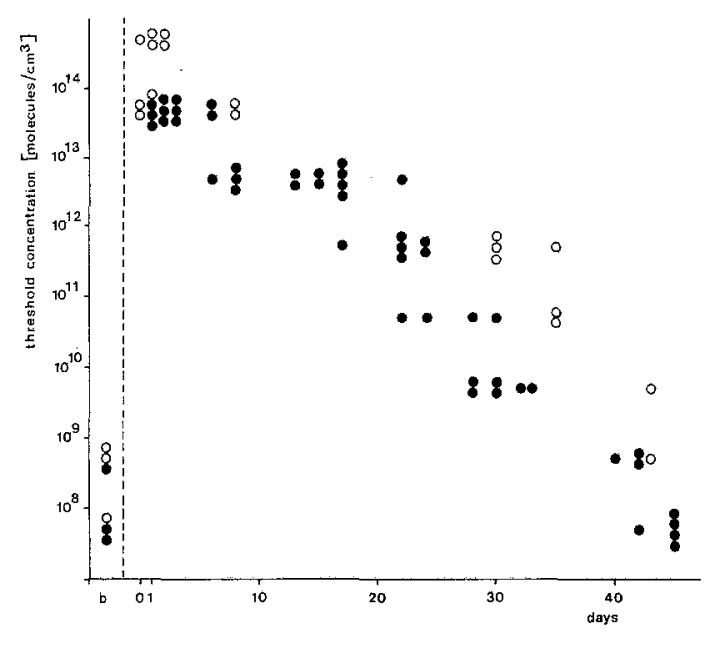

Fig. 3. Neural olfactory thresholds to geraniol before (b) and after exposure to MFM. 0: thresholds 15-20 min after exposure. Filled circles, group A (0.5-s exposure); open circles, group B $(1 \mathrm{~s}$ exposure). Ordinate: threshold concentration (molecules geraniol $/ \mathrm{cm}^{3}$ air); abscissa: days after exposure to MFM

The effect of $\mathrm{N}$-methyl-formimino-methylester on the olfactory sensitivity to geraniol is illustrated in Fig. 3. The increase in threshold, by a factor of $10^{5}-10^{7}$, was already evident in the group-B animals 15-20 min after administration of MFM; in group A the threshold was raised after $24 \mathrm{~h}$ by a factor of $10^{5}-10^{6}$. During the subsequent 45 days there was a gradual increase in sensitivity to geraniol. After 4 weeks the threshold was still elevated by a factor of 10 to 100 in group A. Even with only $0.5 \mathrm{~s}$ of exposure, approximately 40 days were required for olfactory sensitivity to return to normal; recovery from 1-s exposure was even longer.

\section{Discussion}

The neural activity of the olfactory bulb is characterized by two forms of potentials: a slow wave synchronous with breathing, upon which rapid oscillations are superimposed at the end of inspiration. The frequency of these oscillations changes following stimulation with an odorant, indicating that this wave form is associated with processing information in the bulb [7]. Brief exposure to $\mathrm{N}$-methyl-formimino-methylester dramatically alters bulb activity. The amplitude of the slow wave is reduced, and the oscillations are eliminated altogether. The olfactory threshold is raised parallel to the depression of the neural activity. Male albino mice normally have an olfactory threshold for geraniol in the range of $5 \times 10^{7}$ to $5 \times 10^{9}$ molecules $/ \mathrm{cm}^{3}$ air [7]. After exposure to MFM (depending on its duration) the threshold concentration shifts to $5 \times 10^{13}$ to $5 \times 10^{14}$ molecules $/ \mathrm{cm}^{3}$ air. Only two to three inhalations of the gas are sufficient to raise the geraniol threshold by a factor of $10^{5}-10^{6}$. Normal thresholds are not regained until about 6 weeks later.

The immediate onset of olfactory blockade indicates that MFM has a direct action on the function of the olfactory receptor cells. The restoration of bulb activity within $5-6$ weeks shows a recovery process with a time course similar to 
that after destruction of the olfactory epithelium by $\mathrm{ZnSO}_{4}[1,5]$. The changes of olfactory sensitivity are also in agreement with morphological studies of the epithelium after MFM-blockade [6]. Although no alterations in the sensory cell layer could be observed during the first day after application of MFM, the rate of mitosis in the progenitor cell layer incrases during the first $1.5 \mathrm{~h}$. In the course of $2-3$ weeks the sensory cells degenerate gradually and the mitotic rate of the progenitor cells remains elevated. After about 5 weeks the epithelium is nearly fully regenerated and the olfactory thresholds have also returned to normal.

$\mathrm{N}$-methyl-formimino-methylester is an extremely effective and rapidly acting olfactory blocking agent. In spite of its severe side effects, and the fact that the effective concentration is only slightly less than the $\mathrm{LD}_{50}$, this substances may be a useful tool for studying olfactory mechanisms.

\section{References}

1. Alberts JR (1974) Producing and interpreting olfactory deficits. Physiol Behav 12:657-670

2. Bredereck $H$ (1965) Mitteilung. Nachr Chem Techn 13:66

3. Bredereck H, Effenberger F, Henseleit E (1965) Umsetzungen von N-Monoalkyl-form- und -acetamiden mit Dimethylsulfat - Synthesen von N-Monoalkyl-imidsäureestern und symmetrischen N.N'-Dialkylformamidinen. Chem Ber 98:2754-2761

4. Herberhold C (1975) Funktionsprüfungen und Störungen des Geruchssinnes. Arch Otorhinolaryngol 210: $67-164$

5. Matulionis DH (1975) Ultrastructural study of mouse olfactory epithelium following destruction by $\mathrm{ZnSO}_{4}$ and its subsequent regeneration. Am J Anat 142:67-90

6. Rehn B, Breipohl W, Schmidt C, Schmidt U, Effenberger F (1981) Chemical blockade of olfactory perception by $\mathrm{N}$-methyl-formiminomethylester in albino mice. II. Light microscopical investigations. Chem Senses $6: 317-328$

7. Schmidt C (1982) Behavioural and neurophysiological studies of the olfactory sensitivity in the albino mouse. Z Säugetierk 47:162-168

8. Schmidt U (1978) Evoked-potential measurement of olfactory thresholds of laboratory mice (Mus musculus) to caboxylic acids. Chem Sens Flav 3: 177-182 